\title{
Femoroacetabular Impingement: Saving the Joint
}

\author{
Ronald Huang \\ Thomas Jefferson University \\ Javad Parvizi \\ The Rothman Institute of Orthopedics at Thomas Jefferson University, 925 Chestnut Street, Philadelphia, \\ PA 19107, USA
}

Follow this and additional works at: https://jdc.jefferson.edu/orthofp

Part of the Musculoskeletal Diseases Commons, Musculoskeletal System Commons, and the Orthopedics Commons

\section{Let us know how access to this document benefits you}

\section{Recommended Citation}

Huang, Ronald and Parvizi, Javad, "Femoroacetabular Impingement: Saving the Joint" (2011).

Department of Orthopaedic Surgery Faculty Papers. Paper 32.

https://jdc.jefferson.edu/orthofp/32

This Article is brought to you for free and open access by the Jefferson Digital Commons. The Jefferson Digital Commons is a service of Thomas Jefferson University's Center for Teaching and Learning (CTL). The Commons is a showcase for Jefferson books and journals, peer-reviewed scholarly publications, unique historical collections from the University archives, and teaching tools. The Jefferson Digital Commons allows researchers and interested readers anywhere in the world to learn about and keep up to date with Jefferson scholarship. This article has been accepted for inclusion in Department of Orthopaedic Surgery Faculty Papers by an authorized administrator of the Jefferson Digital Commons. For more information, please contact: JeffersonDigitalCommons@jefferson.edu. 


\title{
As submitted to:
}

\section{Seminars in Arthroplasty}

\author{
And later published as:
}

\section{Femoroacetabular Impingement: Saving the Joint}

\author{
Volume 22, Issue 2, June 2011, Pages: 52-55
}

\section{DOI: 10.1053/j.sart.2011.03.001}

Ronald Huang, BS, and Javad Parvizi, MD, FRCS

Many factors have been linked to the development of osteoarthritis (OA) of the hip, but often, cases are still considered "idiopathic." Femoroacetabular impingement (FAI) has been suggested as a possible etiologic factor for the otherwise "idiopathic" cases. It is theorized that the subtle morphologic abnormalities seen at the head-neck junction and acetabulum in FAI may lead to labral tears, chondral damage, and subsequent progression of OA. Prevalence of FAI has been suggested to be as high as $14 \%$ in the general population. It often presents in young active patients that subject their hip joint to repetitive micro trauma associated with impingement of the osseous deformity within normal ranges of motion. Current surgical treatment options for FAI include arthroscopy, open surgical dislocation, or mini-open direct anterior osteoplasty. All methods are directed at correcting the osseous abnormalities and associated pathologies in hopes of delaying the progression of OA and the need for hip replacement. Limited short term followup data has shown significant improvement in pain and function following each of the three procedures. However, long term follow-up and comparative studies are necessary to evaluate then efficacy of each of the surgical approaches in delaying the progression of osteoarthritis.

KEYWORDS FAI, femoroacetabular impingement, hip, labral tear, osteoplasty 


\section{Femoroacetabular Impingement: Saving the Joint}

Ronald Huang, BS, and Javad Parvizi, MD, FRCS

A work group developed a definition of osteoarthritis (OA) in the late 1990s that included a class of "idiopathic" OA, in addition to well-established causes, such as trauma and dysplasia." However, recent studies have theorized that even "idiopathic" OA stems from an underlying mechanical abnormality that leads to damage of some or all the tissues in the synovial joint. 2 Specifically, Ganz et $\mathrm{al}^{3}$ popularized the concept of femoral acetabular impingement (FAI), which involves abutment of the acetabular rim against the femoral head-neck region within normal ranges of motion, causing damage to the articular cartilage and labrum. With the understanding that $\mathrm{OA}$ is secondary to mechanical damage and subsequent failure of tissues within the joint, in theory, correcting the mechanical problem and restoring the biomechanics of the hip should delay the degenerative process. This is the basis upon which surgery for FAI is performed. FAI can manifest as anatomic abnormality in 2 main areas of the hip joint. An out-ofround femoral head with extra bone at the femoral head_neck junction impinges against the acetabular rim in flexion and internal rotation, ie, Cam type FAI (Fig. 1). The Cam lesion often causes labral detachment and an outside-in delamination of the acetabular articular cartilage as the oversized femoral head forces itself under the acetabular rim. Overcoverage of the femoral head by the acetabulum can also cause damage to the joint, or pincer-type FAI (Fig. 2). In flexion and internal rotation, the labrum is compressed between the head_neck region and acetabular rim, leading to degeneration and eventually ossification of the labrum, worsening the problem of overcoverage. Exacerbation of both types of impingement cause disruption of the synovial joint, decreasing the amount of synovial fluid sealed within the joint and increasing the load transfer within cartilage layers of the hip because of development of chondral lesions. ${ }^{4}$

\section{Clinical Presentation of FAI}

FAI typically presents in young, physically active adults. Patients often report onset of groin pain after minor trauma to the hip. Their symptoms gradually worsen and are exacerbated by continued athletic activity, prolonged sitting, and prolonged walking. However, these clinical symptoms are fairly nonspecific, and FAI is a subtle abnormality on radiographs. Without a focused physical examination and the correct diagnostic tests, the diagnosis of FAI can be missed, and patients often undergo unnecessary diagnostic workups and procedures, such as laparoscopy, hernia repair, and knee arthroscopy. ${ }^{3}$ On physical examination, patients have often 
have restricted flexion and internal rotation of the affected hip. Impingement test is positive; flexion to $90^{\circ}$, internal rotation, and adduction of hip reproduces their pain. This is caused by shearing forces at the junction of the femoral neck and acetabular rim that cause a sharp pain where there is a labral tear or chondral lesion. Stinchfield test, Log roll test, Thompson test, and other provocative maneuvers may be positive, but are nonspecific for FAI. ${ }^{5}$

\section{Radiographic and Magnetic \\ Resonance Imaging in FAI}

Radiographs are a low-cost and easily obtained first-line screening tool for patients with hip pain. Many radiographic signs and measurements may indicate FAI and associated labral pathologies. In Cam-type deformity of the femoral head, there is a decrease in femoral neck offset, and the femoral head appears nonspherical. Ossicles extending from the acetabular rim may be present, suggesting ossification of the labrum. Synovial herniation pits have also been associated with the area of impingement. ${ }^{6} \mathrm{MR}$ arthrogram is essential to confirm and quantify lesions in the synovial joint where FAI is suspected. A classic triad of findings is present in FAI: abnormal alpha angle, labral tear, and chondral injury. ${ }^{7}$ Alpha angle is measured by first drawing a circle that outlines the acetabular portion of the femoral head, drawing one line of the angle from the center of the femoral head along the axis of the femoral neck, and the other part of the angle from the center of the femoral head to the point where the osseous femoral head intersects the circle (Fig. 3). An alpha angle of $55^{\circ}$ is considered abnormal.

\section{Treatment of FAI}

Nonoperative treatment is generally unsuccessful for FAI. Patients report continued hip pain during activity despite the regular use of nonsteroidal anti-inflammatory drugs for pain control. Additionally, they report a dramatic restriction in daily and athletic activities secondary to pain.5 Surgical intervention, ie, femoral acetabular osteoplasty (FAO), has been shown to reduce pain and restore physical activity level in patients with FAI with minimal to no evidence of arthritis. It has 3 main goals: to reshape the femoral head-neck region and/or acetabular rim to eliminate the osseous impingement, to repair torn labrum to the acetabulum if possible, and to perform microfracture and/or excision of chondral lesions. It is theorized that correcting the underlying mechanical pathology in FAI will help delay the progression of hip arthritis. ${ }^{2}$

\section{Surgical Candidate Selection}

As with other elective procedures, appropriate patient selection for FAO is extremely important to provide optimal chance for success. A recent case series demonstrated that patients with Tönnis 2 arthritis had significantly less chance of improvement (58\%) than patients with Tönnis 0 or 1 arthritis (94\% and 95\%, respectively). ${ }^{8}$ Even slight joint space narrowing, however, may indicate severe cartilage damage, which will affect axial loading and limit the possibility of improvement. ${ }^{9}$ Therefore, patients with FAI and significant degenerative joint disease should be treated nonoperatively until they are ready for a total hip replacement. Not all patients with labral tears are candidates for surgery. Pain out of proportion for a labral tear and lack of relief from an intra-articular injection of anesthetic indicates that the patient's pain is unlikely to be resolved with surgery for FAI and labral tear. In addition, patients with worker's compensation, legal cases, and psychological problems are likely to do poorly after surgery.

\section{Outcomes of Surgery}


The ideal surgical procedure to treat FAI has yet to be determined. Currently, open surgical dislocation, arthroscopy, and a mini-open procedure are used to perform osteoplasty. Open surgical dislocation was the first technique developed to correct the abnormal morphology, described by Ganz et al in 2001. ${ }^{10}$ The procedure involves a lateral incision, greater trochanteric flip osteotomy, z-shaped capsulotomy, and an anterior dislocation of the hip. This approach preserves the femoral head blood supply and provides direct visualization of the complete hip joint, allowing intra-articular lesions to be addressed. Peters et $\mathrm{al}^{11}$ reported on a series of 96 hips with FAI treated with open surgical dislocation. There were no cases of osteonecrosis postoperatively but one case of early failure of greater trochanteric fixation and one nonunion. Harris Hip scores improved from 67 preoperatively to 91 postoperatively at an average follow-up of 26 months. Similarly, Espinosa et $\mathrm{al}^{9}$ reported on a series of 60 hips treated with open surgical dislocation that had statistically significant improvement in clinical scores at 2 years.

Although surgical dislocation for FAI offers visualization of all affected structures in the synovial joint, it is a traumatic procedure that requires a long period of nonweight-bearing activity during recovery and has the risk of greater complications because of the greater trochanteric osteotomy. In some young athletic patients, this procedure may have an unacceptable recovery period and preclude them from returning to high-impact activities. Arthroscopy offers a minimally invasive approach and short recovery period and at the same time aims to accomplish similar goals of osteoplasty, labral repair, and microfracture for chondral lesions. In addition, there is a minimal scar and blood loss. However, visualization of affected structures is technically difficult, the hip must be held in prolonged traction, and it is difficult to perform adequate osteoplasty of the femoral head-neck region. ${ }^{12}$ Nevertheless, investigators have shown that arthroscopic treatment of FAI and associated labral tears can allow early return to sports in professional athletes. ${ }^{13}$

The mini-open direct anterior procedure aims to combine the benefits of a minimally invasive procedure with direct visualization of involved structures. In addition, this approach enables surgeons to test range of motion intraoperatively and repeat osteoplasty until the desired range of motion is obtained, sparing the patient major morbidity, such as trochanteric osteotomy in surgical dislocation or prolonged traction during arthroscopy. The downside to this procedure is the inability to access the infer-posterior labrum and central articular compartment. However, most lesions in patients with FAI are present in the antero-superior region of the joint. Postoperatively, patients are able to quickly return to full weight bearing activity at 6 weeks. Ribas et al ${ }^{8}$ published a series of 117 hips that underwent mini-open FAO that shows significant clinical and functional improvement, especially those with Tönnis 1 and Tönnis 2 arthritis. From our institutional experience, of 82 patients that underwent mini-open direct anterior FAO by the senior author (J.P.) that have reached at least 1 year of follow-up, 78 experienced significant improvements in their function, measured by modified Harris hip score, SUSHI (ie, SUper Simple HIp) score, and UCLA score. Four patients required subsequent total hip arthroplasty for progression of arthritis. ${ }^{14}$ All 3 current approaches to treating FAI have demonstrated efficacy for resolving pain and restoring activity in their respective case series. However, longer-term studies are needed to evaluate the efficacy of these procedures in delaying the progression of hip arthritis, and randomized trials are needed to compare the efficacy of the various approaches.

\section{References}


1. Flores R, Hochberg M: Definition and classification of osteoarthritis, in Brandt K, Doherty M, Lohmander L (eds): Osteoarthritis. New York, Oxford University Press, 1998, pp 1-12

2. Brandt KD, Dieppe P, Radin EL: Etiopathogenesis of osteoarthritis. Rheum Dis Clin North Am 34:531-559, 2008

3. Ganz R, Parvizi J, Beck M, et al: Femoroacetabular impingement: A cause for osteoarthritis of the hip. Clin Orthop Relat Res 417:112-120, 2003

4. Ferguson SJ, Bryant JT, Ganz R, et al: An in vitro investigation of the acetabular labral seal in hip joint mechanics. J Biomech 36:171-178, 2003

5. Jaberi FM, Parvizi J: Hip pain in young adults: Femoroacetabular impingement. J Arthroplasty 22:37-42, 2007

6. Leunig M, Beck M, Kalhor M, et al: Fibrocystic changes at anterosuperior femoral neck: Prevalence in hips with femoroacetabular impingement. Radiology 236:237-246, 2005

7. Kassarjian A, Yoon LS, Belzile E, et al: Triad of MR arthrographic findings in patients with cam-type femoroacetabular impingement. Radiology 236:588-592, 2005

8. Ribas M, Ledesma R, Cardenas C, et al: Clinical results after anterior mini-open approach for femoroacetabular impingement in early degenerative stage. HIP Int 20(suppl 7):36-42, 2010

9. Espinosa N, Beck M, Rothenfluh DA, et al: Treatment of femoro-acetabular impingement: Preliminary results of labral refixation. Surgical technique. J Bone Joint Surg Am 89(suppl

2):36-53, 2007

10. Ganz R, Gill TJ, Gautier E, et al: Surgical dislocation of the adult hip a technique with full access to the femoral head and acetabulum without the risk of avascular necrosis. J Bone Joint Surg Br 83:1119-1124, 2001

11. Peters CL, Schabel K, Anderson L, et al: Open treatment of femoroacetabular impingement is associated with clinical improvement and low complication rate at short-term followup. Clin Orthop Relat Res 468: 504-510, 2010

12. Vaughn ZD, Safran MR: Arthroscopic femoral osteoplasty/chielectomy for cam-type femoroacetabular impingement in the athlete. Sports Med Arthrosc 18:90-99, 2010

13. Philippon MJ, Weiss DR, Kuppersmith DA, et al: Arthroscopic labral repair and treatment of femoroacetabular impingement in professional hockey players. Am J Sports Med 38:99-104, 2010

14. Parvizi J, Huang R, Matar W, et al: Mini-open direct anterior approach for the treatment of femoroacetabular impingement, 2010 Available at:

http://www3.aaos.org/education/anmeet/anmt2010/poster/poster.cfm? Pevent_P104. Accessed: December 25 . 
Figure 1 Cam-type tmpingement.

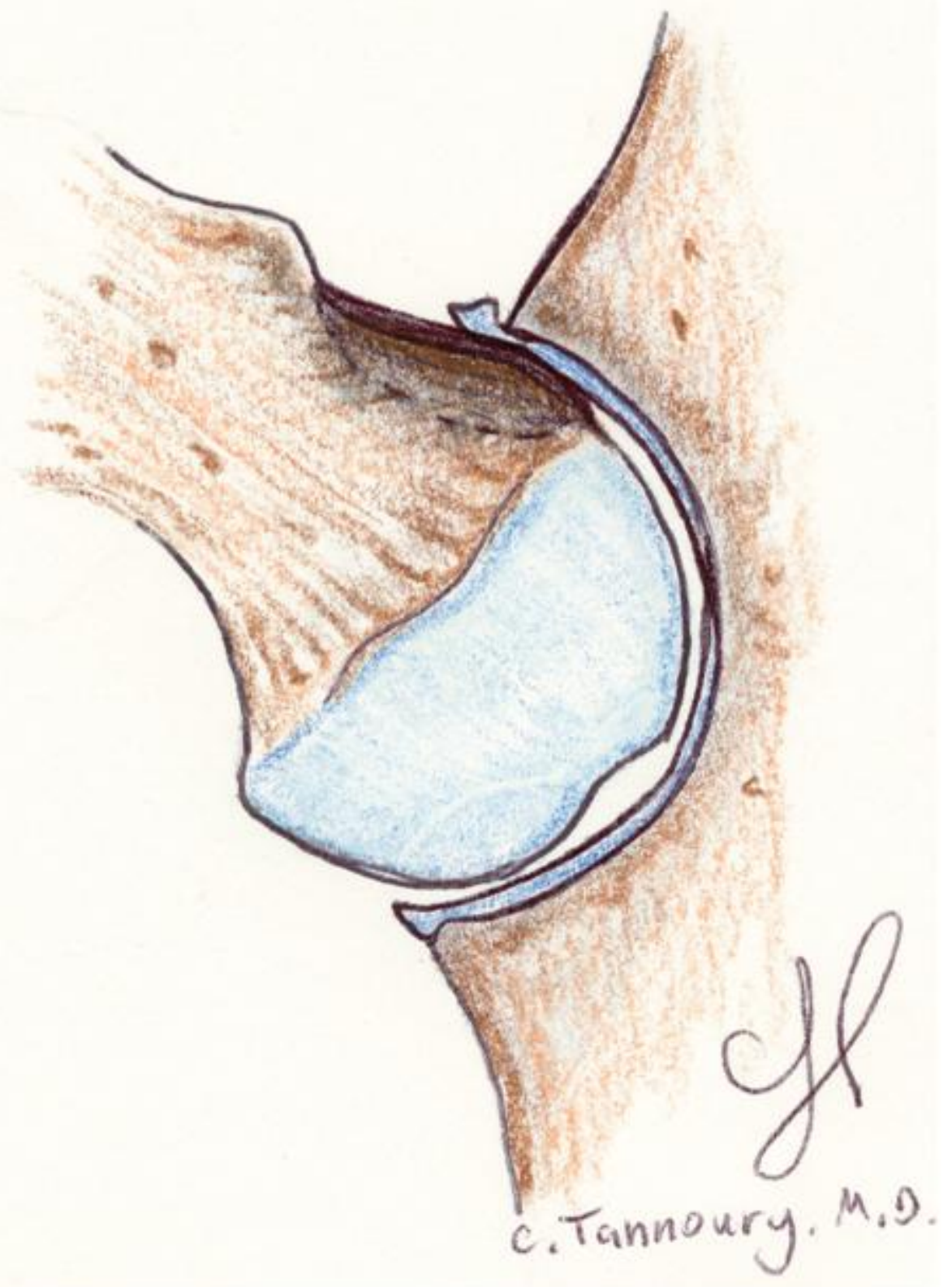


Figure 2 Pincer-type tmpingement.

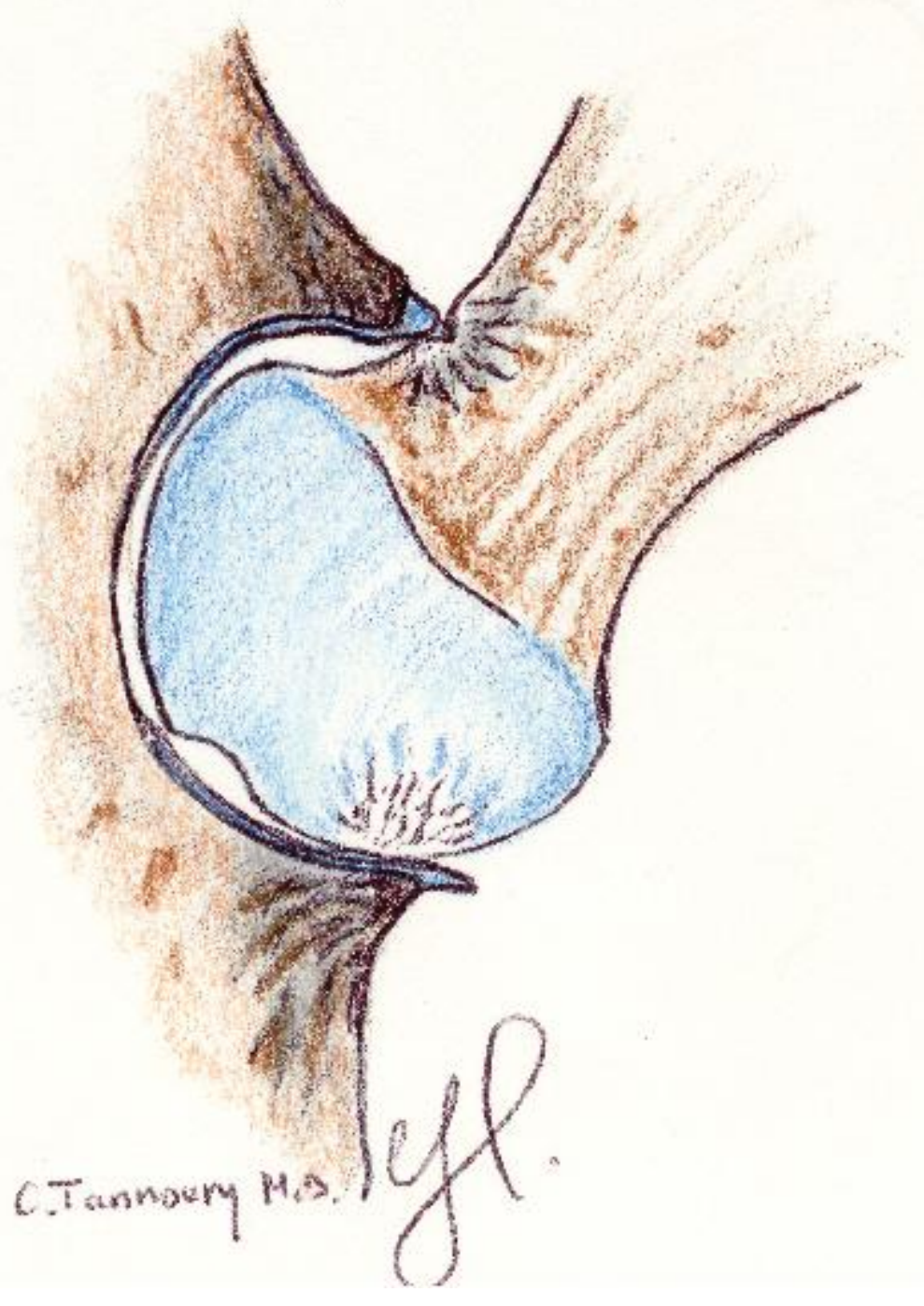


Figure 3 (A) Normal alpha angle of $55^{\circ}$.

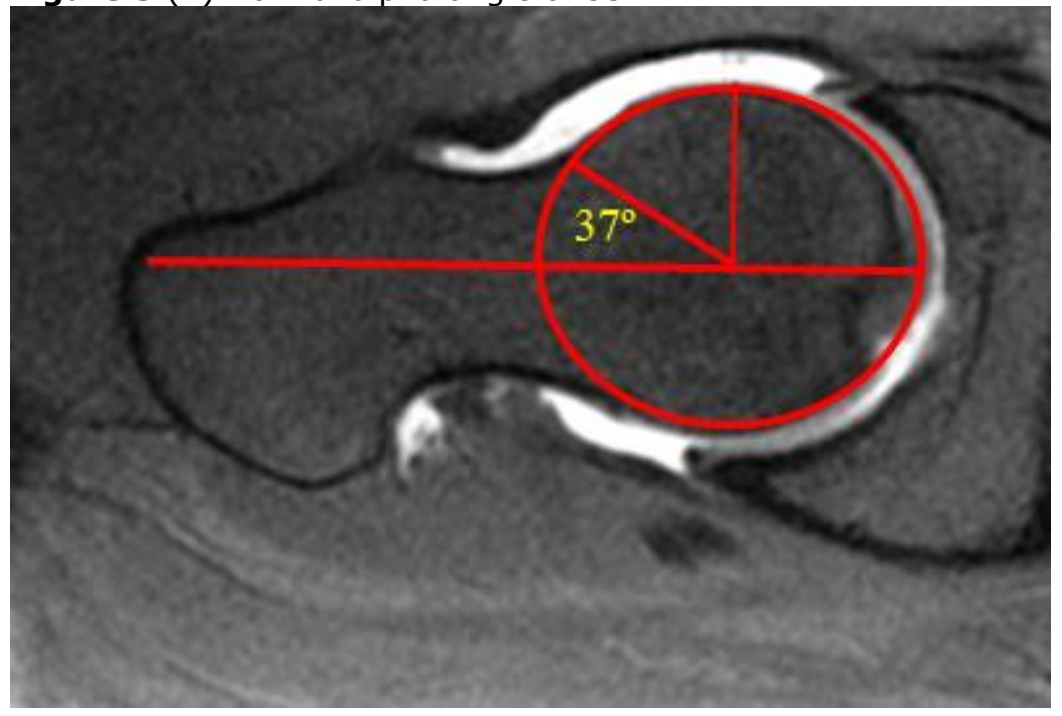

Figure 3 (B) Abnormal alpha angle of $55^{\circ}$.

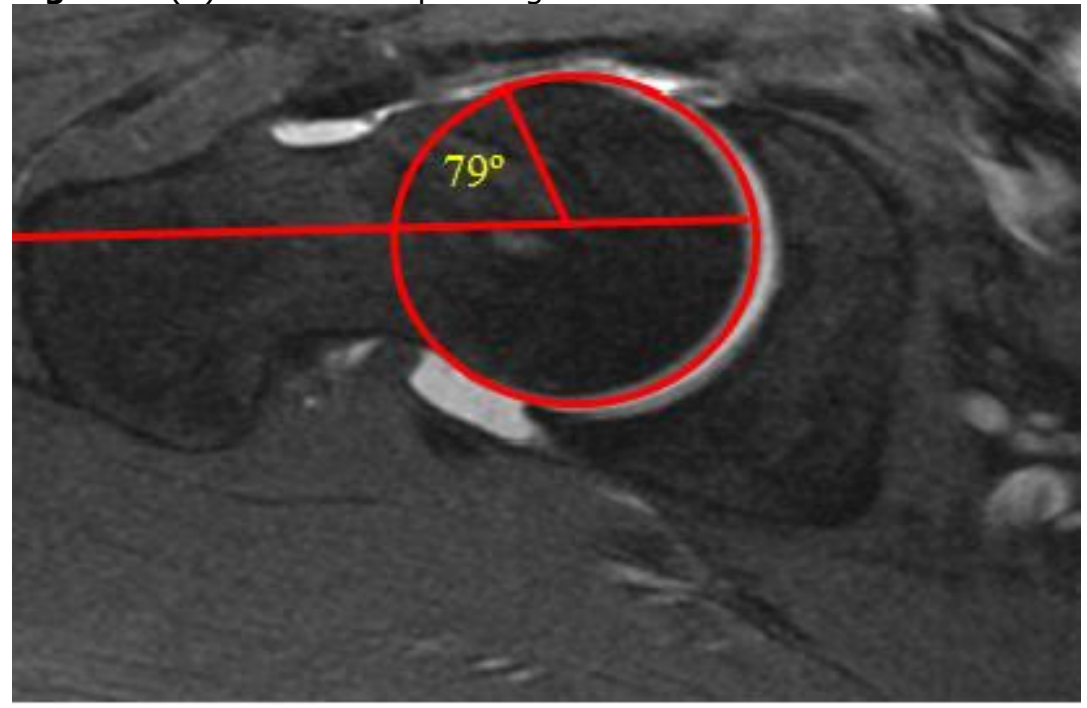


Disclosures: Department of Orthopedic Surgery and Rothman Institute at Thomas Jefferson University Hospital, Philadelphia, PA. Dr. Parvizi has received research support from NIH, OREF, DOD, Aircast, AOA, MTF, Stryker Orthopaedics, Pfizer, The Knee Society, Kimberly Clark, Ortho McNeill, Adolor, Cubist, 3M, Zimmer, Biomemetics, Wyeth, Canadian Health; is a board member of C.D. Diagnostics, Philadelphia Orthopedics, Eastern Orthopedics, and United Healthcare; and a consultant for Stryker, Orthopaedics, Zimmer, Biomet, Smith\&Nephew, Convatech; has intellectual property with Smartech, and Cyrumed. 